\title{
Mouse Models of Hepatitis B Virus Pathogenesis
}

\author{
Matteo lannacone ${ }^{1,2}$ and Luca G. Guidotti ${ }^{1,3}$ \\ ${ }^{1}$ Division of Immunology, Transplantation and Infectious Diseases, IRCCS San Raffaele Scientific Institute, \\ 20132 Milan, Italy \\ ${ }^{2}$ Vita-Salute San Raffaele University, 20132 Milan, Italy \\ ${ }^{3}$ Department of Immunology \& Microbial Sciences, The Scripps Research Institute, La Jolla, California 92037 \\ Correspondence: matteo.iannacone@hsr.it; guidotti.luca@hsr.it
}

\begin{abstract}
The host range of hepatitis B virus (HBV) is limited to humans and chimpanzees. As discussed in the literature, numerous studies in humans and chimpanzees have generated a great deal of information on the mechanisms that cause viral clearance, viral persistence, and disease pathogenesis during acute or chronic HBV infection. Relevant pathogenetic studies have also been performed in those few species representing natural hosts of hepadnaviruses that are related to $\mathrm{HBV}$, such as the woodchuck hepatitis virus and the duck hepatitis virus. Further insight has been gained from multidisciplinary studies in transgenic or humanized chimeric mouse models expressing and/or replicating HBV to varying degrees. We provide here a concise summary of the available HBV mouse models as well as of the contributions of these models to our understanding of HBV pathogenesis.
\end{abstract}

$\mathrm{H}^{\mathrm{s}}$ BV replicates noncytopathically in the hepatocyte and most of the clinical syndromes associated with $\mathrm{HBV}$ infection reflect the immune response, particularly the adaptive immune response (see below). Studies on HBV immunobiology have been hampered by the restricted host range of this virus and by the lack of readily infectable small animal models with a well-defined immune system. Over the last two decades, however, many questions pertaining to the immune-mediated mechanisms responsible for disease pathogenesis and viral clearance have been successfully addressed in mouse models. The various mouse models used and the most significant findings that have emerged from such models are the subject of this review.

\section{MOUSE MODELS OF HBV INFECTION}

Many efforts over the last few years have concentrated on the development of mouse models of HBV infection that are based on the use of the natural cellular target of HBV, the human hepatocyte. Human hepatocytes cannot be propagated in vitro as they rapidly lose their highly differentiated status and, consequently, their susceptibility to HBV infection (Dandri and Lütgehetmann 2014). The creation of mice carrying human hepatocytes that retain susceptibility to $\mathrm{HBV}$ has overcome this limitation (Dandri and Lütgehetmann 2014). Chimeric mice harboring human cells have long been used in research, but the advent of mice de-

Editors: Christoph Seeger and Stephen Locarnin

Additional Perspectives on Hepatitis B and Delta Viruses available at www.perspectivesinmedicine.org

Copyright (C) 2015 Cold Spring Harbor Laboratory Press; all rights reserved; doi: 10.1101/cshperspect.a021477

Cite this article as Cold Spring Harb Perspect Med 2015;5:a021477 
ficient in T cells, B cells, natural killer (NK) cells, and the common $\gamma$-chain of the interleukin-2 receptor yielded animals completely unable to reject human cells (Grompe and Strom 2013).

The first mouse model engineered to be engrafted with human hepatocytes (the so-called "Trimera" mouse) was developed by implanting human liver fragments under the kidney capsule of irradiated wild-type mice that were then reconstituted with immunodeficient bone marrow (Ilan et al. 1999). By infecting ex vivo the human liver specimens with HBV before implantation into the mouse, low levels of viremia could be detected in most of the implanted animals (Ilan et al. 1999). Because of the ectopic location of the implanted tissue, however, human hepatocytes remained functional only for a limited time and in vivo infection with HBV could not be established (Ilan et al. 1999).

To achieve long-term in vivo survival of highly differentiated human hepatocytes potentially permissive for HBV infection, major attempts were made to generate mice capable of accommodating human hepatocytes within the liver parenchyma. To date, several mouse models have been established (Grompe and Strom 2013; Dandri and Lütgehetmann 2014). The basic idea is to induce destruction of mouse hepatocytes to create the space, the liver regenerative stimulus, and the selective growth advantage that are necessary for transplanted hepatocytes to expand and reconstitute the diseased mouse liver (Dandri and Lütgehetmann 2014), for example, by using hepatocytes freshly isolated from the liver of patients or cryopreserved in tissue banks. Initial studies used the albumin-uroplasminogen activator (uPA) transgenic mice that became available in the early 1990s (Heckel et al. 1990; Rhim et al. 1994). Constitutive expression of uPA in mouse hepatocytes causes hepatic injury and, thus, permits the selective expansion of human hepatocytes that can be infected with HBV (Dandri 2001). The uPA mouse model, however, has certain limitations. These include excessive mortality, low breeding efficiency, reversion of constitutive expression of the uPA transgene, and the necessity to transplant hepatocytes within the first month of life. In 2007, two groups reported the establishment of an alternative chimeric model for creation of hepatocyte chimeric mice, based on the use of fumaryl acetoacetate hydrolase (FAH)-deficient mice. This model overcame most limitations of the uPA mouse model (Azuma et al. 2007; Bissig et al. 2007, 2010). FAH plays a crucial role in the tyrosine catabolic pathway, and its deficiency leads to hypertyrosinemia and liver failure. However, accumulation of toxic metabolites can be avoided by treating the mice with a pathway inhibitor, the drug NTBC (2-(2-nitro-4-trifluoromethylbenzoyl)-1,3-cyclohexanedione), which protects the mice from liver injury until the drug is withdrawn. Additional mouse models for human hepatocyte transplantation were later developed, including the TKNOG and the AFC8 mouse models. In these models, the hepatotoxic transgene can be conditionally activated with ganciclovir and AP20187, respectively (Washburn et al. 2011; Kosaka et al. 2013).

Although studies describing a direct comparison among the different models are not available, current data suggest that all four models exhibit similar properties, once high human hepatocyte chimerism is achieved (Grompe and Strom 2013). Despite limitations that include high costs, low throughput, significant individual variability in engraftment of human hepatocytes and viral replication levels, and the lack of nonparenchymal liver cells of human origin, mice with humanized livers are potentially useful for evaluating specific steps of the HBV life cycle, including viral entry and the formation of covalently closed circular DNA (cccDNA), and evaluation of antiviral compounds that target those steps. Of note, cccDNA is derived from relaxed circular (rc) genomic DNA, which is contained within capsid particles that are transported into the hepatocyte nucleus (Ganem and Prince 2004); cccDNA formation from rc genomic DNA is most likely performed by host enzymes; cccDNA is then assembled into an episomal "minichromosome."

Because chimeric animals are generally made from immunodeficient mice, they are not suited for immunological and/or immunopathological studies. The generation of chimeric 
mice equipped with both human hepatocytes and a fully functional major histocompatibility complex (MHC)-matched human immune system derived from the same fetal liver could potentially solve this issue; work on this system is currently pursued in several laboratories. The advent of methods to derive functional hepatocytes and mature immune cells from induced pluripotent stem cells obtained from the same human donor also opens up new opportunities for the future development of immunologically competent chimeric mice (Lim et al. 2013; Zhu et al. 2014).

New transgenic mouse models of HBV infection might also arise following the recent discovery of sodium taurocholate cotransporting polypeptide (NTCP) as the cellular receptor of HBV (Yan et al. 2012). Thus far, however, mouse hepatocytes engineered to express the human NTCP appear not to support the establishment of productive HBV infection (Li et al. 2014). As in HBV-replication, competent transgenic mice (see below), this finding suggests that the restriction of HBV in mouse hepatocytes likely occurs after viral entry but before cccDNA formation and transcription of viral mRNAs. Thus, development of HBV-susceptible mice awaits identification of the factors that restrict cccDNA formation in this host.

\section{MODELS OF DISEASE}

\section{Acute Hepatitis}

Definitive analyses of the immunological mechanisms of HBV pathogenesis required the development of easy-to-manipulate mouse models with a well-defined immune system. Thus far, a large amount of the cellular and molecular pathogenic or antiviral mechanisms that may occur during acute viral hepatitis in man has been recapitulated in HBV-replication-competent transgenic mice. Two lineages of HBV transgenic mice, termed 1.3.32 and 1.3.46, have been produced, whose hepatocytes replicate the virus at high levels without any evidence of cytopathology (Guidotti et al. 1995). These mice were created by microinjection of a terminally redundant viral DNA construct $1.3 \mathrm{HBV}$
Mouse Models of Hepatitis B Virus Pathogenesis

genomes in length, containing only HBV promoters and enhancers (Fig. 1, top). All four HBV RNAs are produced in the liver of these animals. The two most abundant transcriptional products of the transgene are the 3.5- and 2.1kb RNA, easily detectable by Northern blot (NB) analysis (Fig. 1). The $3.5-\mathrm{kb}$ pregenomic RNA is reverse transcribed by the viral polymerase into HBV DNA replicative intermediates, which appear as a smear on Southern blots (SB) (Fig. 1). HBV replication in these mice occurs inside viral nucleocapsids (Fig. 1, inset), preferentially in centrilobular hepatocytes. As a consequence of efficient viral replication, infectious viral particles that are morphologically indistinguishable from human-derived virions are present in transgenic mouse serum at levels up to $10^{7}$ to $10^{8}$ viral particles per $\mathrm{ml}$ (Guidotti et al. 1995). Interestingly, cccDNA, the viral transcriptional template during natural infections, is not readily detectable in hepatocytes of HBV transgenic mice (Guidotti et al. 1995). However, low levels of cccDNA have been found in the livers of these animals after crossing them with hepatocyte nuclear factor $1 \alpha$-null mice, suggesting that the impairment of cccDNA synthesis in mouse hepatocytes is not absolute (Raney et al. 2001). Alternative methods to deliver replication-competent HBV genomes to mouse hepatocytes, such as hydrodynamic injection of naked plasmid DNA and adenovirus- or adeno-associated virus (AAV)-mediated transfer, did not lead to detectable cccDNA formation, confirming the existence of a species restriction on the production of cccDNA (Sprinzl et al. 2001; Yang et al. 2002, 2013; Huang et al. 2011; Dion et al. 2013).

The observation that HBV replicates at high levels in the liver of these immunologically tolerant HBV-replication-competent transgenic mice in the absence of cytological abnormalities or inflammation reiterates data obtained in patients and experimentally infected chimpanzees indicating that $\mathrm{HBV}$ is a noncytopathic virus, which does not readily activate innate immunity (Guidotti and Chisari 2006).

Possibly, the most relevant results obtained in HBV-replication-competent transgenic mice relate to the dissection of the highly complex, 
M. Iannacone and L.G. Guidotti

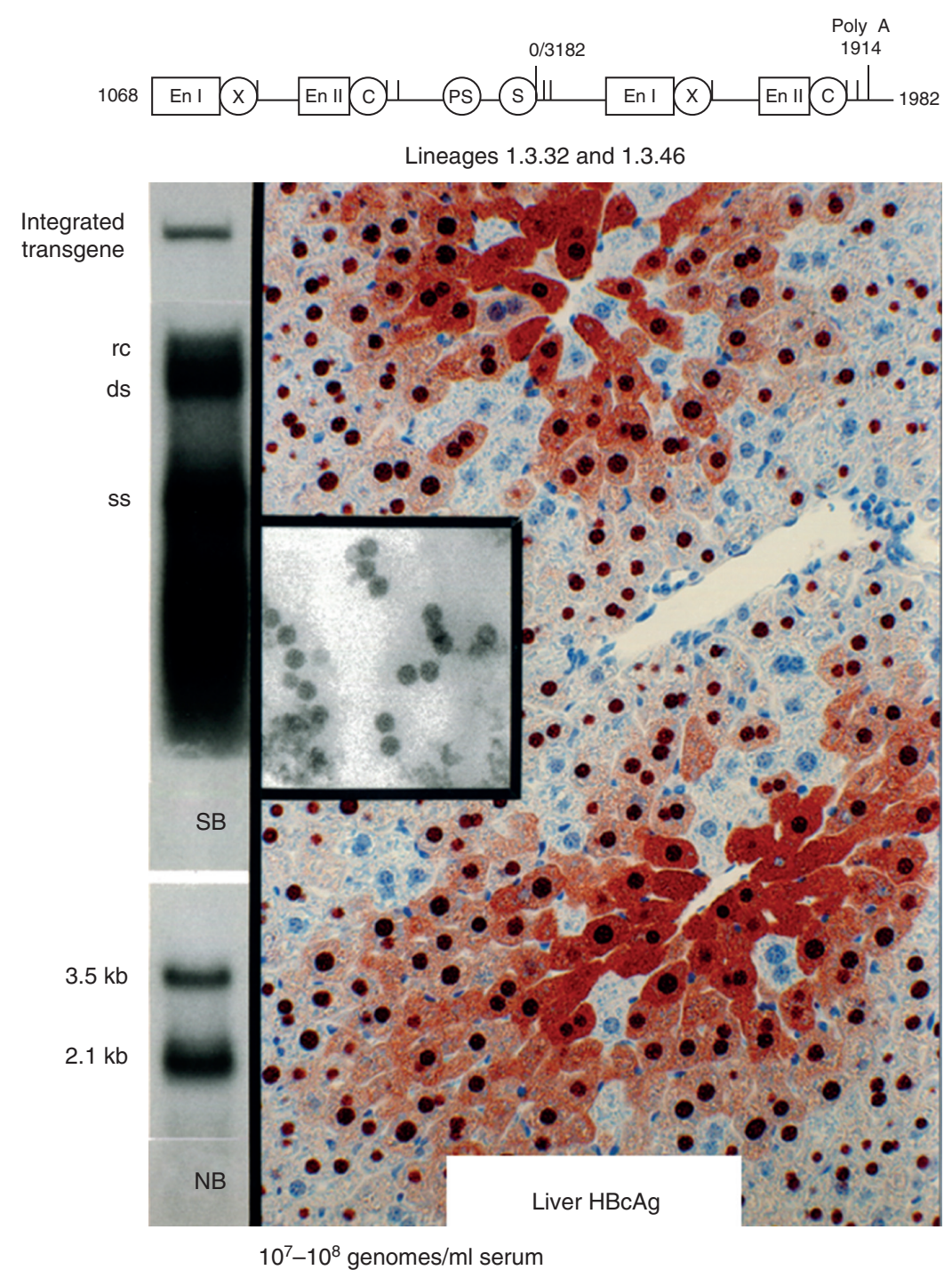

Figure 1. Mice created by microinjection of a terminally redundant viral DNA construct. (Top) Schematic representation of the construct that contains terminally redundant, greater than genome length (1.3 copies) of the complete hepatitis B virus (HBV) genome (ayw subtype) used to produce transgenic mouse lineages 1.3.32 and 1.3.46. The viral enhancers (En I and II) and the X (X), core (C), PreS (PS) and S promoters are indicated. (Left) Southern blot (SB) analysis of total hepatic DNA extracted from lineage 1.3.32 and hybridized with a 32P-labeled HBV-specific probe. Bands corresponding to the expected size of the integrated transgene, relaxed circular (rc), double-stranded linear (ds), and single-stranded (ss) HBV DNA are indicated. Northern blot (NB) analysis of total hepatic RNA extracted from lineage 1.3.32 and hybridized with a 32P-labeled HBVspecific probe. Bands corresponding to the expected size of the HBV 3.5- and 2.1-kb RNAs are indicated. (Right) Immunohistochemical analysis of a liver from lineage 1.3.32 shows that nuclear hepatitis B core antigen ( $\mathrm{HBcAg}$ ) is present in almost all of the hepatocytes, whereas cytoplasmic HBcAg is mainly detectable in centrilobular hepatocytes surrounding the central veins (immunoperoxidase stain for HBcAg; original magnification, $200 \times$ ). (Inset) Electron microscopic analysis of hepatic nuclei and cytoplasm from lineage 1.3.32 revealed abundant 25 - to 30 -nm particles that were not present in nontransgenic controls (original magnification, 60,000 $\times$ ). (Bottom) The concentration of HBV virions in the serum of these animals is indicated. Poly A, Polypeptide A. 
but coordinated processes that regulate the host immune response to this virus. Starting with the fundamental role that effector virus-specific $\mathrm{CD}^{+} \mathrm{T}$ cells play in the pathogenesis of viral clearance and liver disease, it was shown that the adoptive transfer of these cells into HBV-replication-competent transgenic mice triggers a necroinflammatory liver disease, which inhibits HBV replication, and shares the same histologic features of acute viral hepatitis in human (Ando et al. 1994; Guidotti et al. 1996). Rapid inhibition of $\mathrm{HBV}$ replication by $\mathrm{CD}^{+} \mathrm{T}$ cells is largely mediated by noncytolytic mechanisms involving the local production of interferon (IFN) $-\gamma$ by these cells (Guidotti et al. 1996). Indeed, it has been reported that IFN- $\gamma$, mostly via its capacity to induce nitric oxide in the liver (Guidotti et al. 2000), prevents the assembly of replication-competent HBV RNAcontaining capsids in the hepatocyte in a proteasome- and kinase-dependent manner (Wieland et al. 2000; Robek et al. 2002, 2004). During this process, the level of viral nucleocapsids in the cytoplasm of hepatocytes rapidly declines, and viral RNAs are destabilized in the cell nucleus by an SSB/La-dependent mechanism (Guidotti et al. 1994, 1996; Tsui et al. 1995; Heise et al. 1999a,b, 2001; Wieland et al. 2000). The notion that IFN- $\gamma$ produced by activated $\mathrm{CD}^{+}$T cells plays a major role in viral clearance has been corroborated by studies in chimpanzees acutely infected with HBV (Guidotti et al. 1999).

As virus-specific $\mathrm{CD} 8^{+} \mathrm{T}$ cells reach the liver parenchyma, they recognize viral antigens and induce hepatocellular apoptosis, the first step in the disease process. The initial apoptotic process, however, involves a relatively small number of hepatocytes. As time progresses, many antigen nonspecific polymorphonuclear and mononuclear inflammatory cells are recruited into the liver, a second step that augments the severity of the disease (Kakimi et al. 2001; Sitia et al. 2002, 2004). Although the recruitment of mononuclear cells mostly depends on chemokines, the recruitment of polymorphonuclear cells largely relies on the recognition of hepatocellular damage. Studies have indeed shown that damage-associated molecular pattern mole-
Mouse Models of Hepatitis B Virus Pathogenesis

cules (DAMPs) such as the high-mobility group box 1 (HMGB1) protein, an abundant nuclear protein acting as an architectural chromatinbinding factor can be passively released by necrotic, but not apoptotic, hepatocytes and chemo-attract polymorphonuclear cells (Sitia et al. 2007, 2011).

Notably, the recruitment process of antigen nonspecific mononuclear or polymorphonuclear cells in the liver of HBV transgenic mice is different from that of virus-specific effector $\mathrm{CD}^{+} \mathrm{T}$ cells - the former is mostly a chemokine- or DAMP-dependent event, whereas the latter largely depends on platelets (Iannacone et al. 2007b). Indeed, using two different models of acute viral hepatitis (HBV transgenic mice as recipients of $\mathrm{HBV}$-specific effector $\mathrm{CD}^{+} \mathrm{T}$ cells and normal inbred mice acutely infected with adenovirus), it was recently shown that platelets are detectable within $\mathrm{CD}^{+}$T cell-containing intrahepatic necroinflammatory foci, alongside apoptotic hepatocytes and inflammatory cells, including effector $\mathrm{CD} 8^{+} \mathrm{T}$ cells (Iannacone et al. 2005). Importantly, platelet depletion greatly ameliorates the severity of liver disease. The profound reduction in liver disease severity observed in platelet-depleted animals is associated with a nearly proportional reduction in the intrahepatic accumulation of virus-specific effector $\mathrm{CD}^{+} \mathrm{T}$ cells, both of which are restored on reconstitution with normal platelets (Iannacone et al. 2005).

The mechanisms through which platelets promote the intrahepatic accumulation of virus-specific effector $\mathrm{CD}^{+} \mathrm{T}$ cells are poorly understood, and efforts to elucidate these processes are actively pursued. Current studies are in agreement with the hypothesis that the peculiar hemodynamic conditions of the liver microcirculation constitutively favor circulating platelets to form small and transient aggregates on the luminal surface of sinusoids; these aggregates appear to represent a preferential surface onto which circulating effector $\mathrm{CD}^{+} \mathrm{T}$ cells arrest their course within the bloodstream (Guidotti et al. 2015). In an ongoing effort to explain mechanistically why platelets are required to support the intrahepatic accumulation of virus-specific $\mathrm{CD}^{+} \mathrm{T}$ cells, it was also found 
that this function is influenced by two specific inhibitors of platelet-activation pathways, aspirin, and clopidogrel that block thromboxane A2 production and the P2Y12 ADP receptor, respectively (Iannacone et al. 2007a). Treating mice with either one, or a combination of the two drugs, attenuates the accumulation of effector $\mathrm{CD}^{+} \mathrm{T}$ cells in the liver and the associated liver damage (Iannacone et al. 2007a).

Interestingly, recent work in the HBV transgenic mouse model indicates that, on entry into the liver, the capacity of virus-specific effector $\mathrm{CD}^{+} \mathrm{T}$ cells to secrete IFN- $\gamma$ rapidly subsides, and this phenotype is maintained until HBV antigens are cleared from the liver (Isogawa et al. 2005). The results suggest that sustained antigen stimulation, as it occurs during chronic infection, may be responsible for the lack of IFN- $\gamma$ production by virus-specific effector $\mathrm{CD}^{+} \mathrm{T}$ cells. This process is followed by the intrahepatic expansion of IFN- $\gamma$-nonproducing virus-specific effector $\mathrm{CD}^{+} \mathrm{T}$ cells with increased cytotoxic capabilities, suggesting that the antiviral (i.e., production of IFN- $\gamma$ ), but not pathogenetic (i.e., killing of hepatocytes) potential of intrahepatic virus-specific effector $\mathrm{CD}^{+} \mathrm{T}$ cells is likely impaired in chronically infected patients (Isogawa et al. 2005). According to this scenario, chronic HBV infection can be characterized by a dysfunctional effector $\mathrm{CD} 8{ }^{+} \mathrm{T}$-cell response that contributes primarily to liver damage rather than to viral clearance, as will be discussed below.

\section{Chronic Hepatitis}

Chronic hepatitis in humans is characterized by a functionally inefficient virus-specific $\mathrm{CD} 8^{+}$ T-cell response that fails to eliminate HBV from the liver but maintains continuous cycles of lowlevel hepatocellular injury, promoting hepatocellular proliferation and exposing proliferating hepatocytes and nonparenchymal cells of the liver to inflammatory mediators (Guidotti and Chisari 2006). Over several decades, the persistence of necrosis, regeneration, and inflammation, coupled with compromised repair functions, are thought to trigger the development of liver fibrosis, cirrhosis, and hepatocellular carcinoma (HCC). Mimicking these very complex immunopathological processes in an animal model, such as the mouse, which is not susceptible to HBV infection and whose lifespan is approximately 2 years, represents a major challenge. Furthermore, all lineages of HBV transgenic mice generated thus far are immunologically tolerant to viral antigens, particularly at the T-cell level, and do not develop acute or chronic hepatitis. Interestingly, several studies using different immunological approaches ranging from dendritic cell immunization to peptide vaccination with $\mathrm{CD}^{+}{ }^{+}$or $\mathrm{CD} 8^{+}$T-cell epitopes in different lineages of $\mathrm{HBV}$ transgenic mice reported that immune tolerance to HBV can be broken, but the magnitude, persistence, and quality of the resultant $\mathrm{T}$-cell responses are not sufficient to establish a model of chronic hepatitis or to achieve an immunotherapeutic antiviral effect (Shimizu et al. 1998; Chen et al. 2001; Sette et al. 2001). Despite these difficulties, a relevant mouse model of immune-mediated chronic hepatitis was generated in the late 1990s (Nakamoto et al. 1998). The model consists of transgenic mice (lineage 107-5) in which the large, middle, and small envelope proteins of HBV are expressed noncytopathically in all hepatocytes. A strong albumin promoter drives expression of the large protein, whereas the endogenous HBV $S$ promoter drives expression of the middle and small proteins (Nakamoto et al. 1998). Replacement of the 107-5-derived tolerant immune system with cells from syngeneic, nontransgenic mice, previously immunized with $\mathrm{HBsAg}$, results in a persistent $\mathrm{HBsAg}$-specific $\mathrm{CD}^{+} \mathrm{T}$ cell response, capable of sustaining low-degree chronic liver disease for the lifespan of the recipient animals (Nakamoto et al. 1998, 2004). Notably, a similar approach in HBV-replicationcompetent transgenic mice does not lead to comparable results (M Iannacone and LG Guidotti, unpubl.). One reason is that the liver of HBV-replication-competent transgenic mice inherently contains a small number of hepatocytes that do not express HBV (Guidotti et al. 1995); these cells replace hepatocytes killed by HBsAg-specific $\mathrm{CD} 8^{+} \mathrm{T}$ cells and repopulate the entire liver within 6 to 8 weeks, arresting the progression of liver disease. 
Studies in the 107-5 chronic hepatitis mouse model helped characterize an immune-mediated basis of hepatocellular transformation during chronic hepatitis. It was shown that the maintenance of low-level liver cell destruction caused by a dysfunctional and detrimental virus-specific $\mathrm{CD} 8^{+} \mathrm{T}$-cell response is sufficient to cause HCC development. In this model, HCC occurred in the absence of cofactors, such as viral integration, $\mathrm{HBV} \mathrm{X}$ gene expression, or genotoxic agents, which have been proposed to contribute to the development of HCC in humans (Nakamoto et al. 1998). Building on the observation that platelets are instrumental to intrahepatic effector $\mathrm{CD}^{+}$T-cell homing, a recent mouse study also showed that clinically achievable doses of the antiplatelet drugs aspirin and clopidogrel, when administered continuously after the onset of liver disease, can prevent hepatocarcinogenesis and greatly improve overall survival (Sitia et al. 2012). These outcomes were preceded by and associated with reduced hepatic accumulation of virus-specific $\mathrm{CD}^{+} \mathrm{T}$ cells and virus-nonspecific inflammatory cells, reduced hepatocellular injury and hepatocellular proliferation, and reduced severity of liver fibrosis (Fig. 2) (Sitia et al. 2012). The observation that antiplatelet therapy inhibits HCC development identifies platelets as key players in the pathogenesis of $\mathrm{HBV}$-associated liver cancer and supports the notion that a sustained immune-mediated necroinflammatory liver disease is sufficient to trigger HCC. Drugs targeting platelet function may, therefore, be a therapeutic option in patients with chronic HBV infections.

Although the above-mentioned studies indicate that chronic immune-mediated liver cell injury is sufficient to trigger HCC, other viral factors are thought to contribute to hepatocarcinogenesis during chronic HBV infection. Indeed, HBV DNA integration has been reported to occur in the proximity of a variety of procarcinogenic genes, including oncogenes, growth factor receptor genes, and genes regulating telomerase activity or signal-transduction pathways, and deregulate their expression (Sung et al. 2012). It should be pointed out, however, that HBV integration might not occur in resting hepatocytes, and, therefore, if this process con-
Mouse Models of Hepatitis B Virus Pathogenesis

tributes to hepatocarcinogenesis, it is likely to be secondary to procarcinogenic events that trigger hepatocyte turnover, such as immunemediated hepatitis. Moreover, the expression of $\mathrm{HBV}$-derived polypeptides such as the X protein, a carboxy-terminally truncated version of the M-HBs protein and the full-length L-HBs protein have been linked to the process of malignant transformation of infected hepatocytes (Bréchot 2004; Kremsdorf et al. 2006; Bréchot et al. 2010). These viral products may contribute to hepatocarcinogenesis by a capacity to activate a variety of cellular promoters and interact with several signal transduction pathways. For instance, the HBV X protein has also been shown to interact and interfere with numerous transcription factors, tumor-suppressor genes, and proteins involved in DNA repair functions (Bréchot 2004; Kremsdorf et al. 2006; Bréchot et al. 2010) Several of these studies have used transgenic mice that overexpress $\mathrm{X}$ and other viral products in the hepatocyte, and further work is required to understand the relevance of these observations in the context of persistent HBV replication and immune-mediated chronic hepatitis.

On a final note, immuno-competent mouse models based on the use of recombinant AAV carrying replication-competent HBV genomes have been recently reported to display varying levels of hepatic HBV gene expression and replication, which are capable of persisting for many months (Huang et al. 2011; Dion et al. 2013; Yang et al. 2013). In one study, the persistence of hepatic HBV expression and replication did not cause liver inflammation and liver pathology because of the induction of regulatory T cells or other mechanisms of peripheral tolerance (Dion et al. 2013). In another study, the authors reported that $\mathrm{AAV}$-infected animals develop HCC by 12-16 months of age (Huang et al. 2011), but it remains to be determined whether such a phenotype is linked to an HBV-specific adaptive immune response. Future work will define whether these various AAV-based systems represent useful platforms to investigate immune mechanisms of $\mathrm{HBV}$ chronicity and/or to test immunotherapeutic approaches to treat $\mathrm{HBV}$ infections. 
M. lannacone and L.G. Guidotti
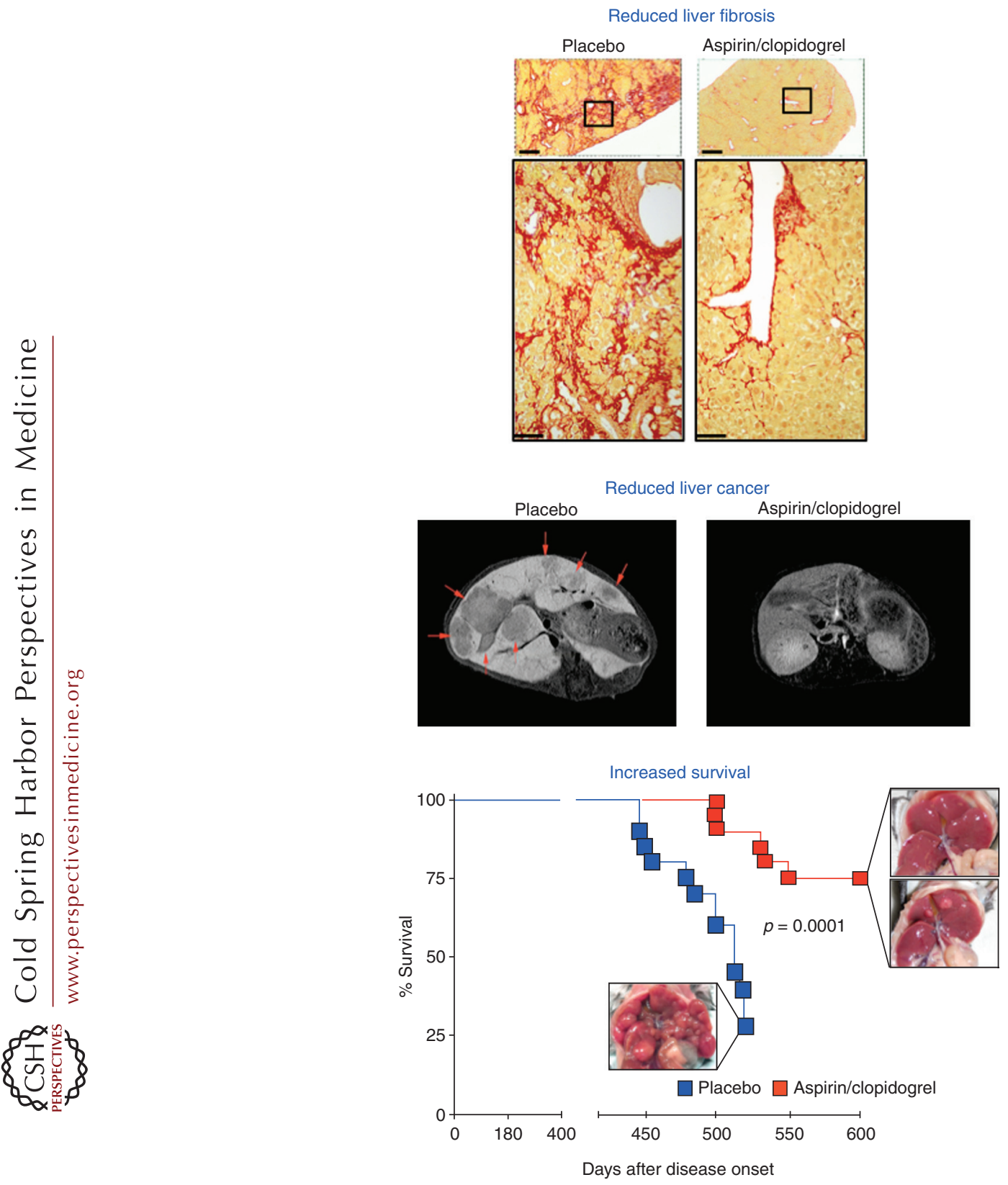

Figure 2. Antiplatelet drugs can prevent hepatocarcinogenesis and greatly improve overall survival. (Top) Micrographs of representative histological liver preparations from the indicated groups of 107-5 mice at day 450 after the onset of immune-mediated chronic hepatitis. Sirius Red staining indicates the relative content of extracellular matrix deposition. Insets indicate areas that are shown below at higher magnification. Scale bars, $500 \mu \mathrm{m}$ (insets); $100 \mu \mathrm{m}$ (blown images). (Middle) Contrast-enhanced liver MRI scans of representative mice from the indicated groups at day 450 after the onset of immune-mediated chronic hepatitis are shown. Red arrows indicate hypointense regions identifying hepatocellular carcinomas (HCCs) after intravenous administration of the contrast agent gadoxetic acid (Primovist). (Bottom) Kaplan-Meier survival curves of the indicated groups of mice (20 mice/group). The statistical significance of differences between mice treated with placebo (diluents) or antiplatelet drugs (aspirin and clopidogrel) is indicated. (From Sitia et al. 2012; adapted, with permission, from the authors.) 


\section{CONCLUDING REMARKS}

Our comprehension of the pathogenesis of $\mathrm{HBV}$ infection has significantly advanced in recent years thanks in part to the experimental use of mouse models. Despite these developments, however, many mechanistic issues pertaining to the biology and immunopathogenesis of $\mathrm{HBV}$ infection remain unresolved, especially those that relate to cccDNA formation and elimination, immune cell priming, and the development of liver fibrosis, cirrhosis, and cancer. Addressing such issues will require the development of novel immunocompetent mouse models susceptible to HBV infection and the refinement of existing models of immune-mediated chronic hepatitis.

\section{ACKNOWLEDGMENTS}

We thank R. Serra for secretarial assistance and the members of the Iannacone and Guidotti laboratories for helpful discussions. This work is supported by European Research Council (ERC) Grants 281648 (to M.I.) and 250219 (to L.G.G); National Institutes of Health (NIH) Grants AI40696 (to L.G.G); Italian Association for Cancer Research (AIRC) Grant 9965 (to M.I.); and a Career Development Award from the Giovanni Armenise-Harvard Foundation (to M.I.).

\section{REFERENCES}

Ando K, Guidotti LG, Wirth S, Ishikawa T, Missale G, Moriyama T, Schreiber RD, Schlicht HJ, Huang SN, Chisari FV. 1994. Class I-restricted cytotoxic T lymphocytes are directly cytopathic for their target cells in vivo. JImmunol 152: $3245-3253$.

Azuma H, Paulk N, Ranade A, Dorrell C, Al-Dhalimy M, Ellis E, Strom S, Kay MA, Finegold M, Grompe M. 2007. Robust expansion of human hepatocytes in $\mathrm{Fah}^{-/-}$/ Rag2 $2^{-/-} / \mathrm{Il} 2 \mathrm{rg}^{-/-}$mice. Nat Biotechnol 25: 903-910.

Bissig KD, Le TT, Woods NB, Verma IM. 2007. Repopulation of adult and neonatal mice with human hepatocytes: A chimeric animal model. Proc Natl Acad Sci 104: 2050720511.

Bissig K-D, Wieland SF, Tran P, Isogawa M, Le TT, Chisari FV, Verma IM. 2010. Human liver chimeric mice provide a model for hepatitis $\mathrm{B}$ and $\mathrm{C}$ virus infection and treatment. J Clin Invest 120: 924-930.
Bréchot C. 2004. Pathogenesis of hepatitis B virus-related hepatocellular carcinoma: Old and new paradigms. Gastroenterology 127: S56-S61.

Bréchot C, Kremsdorf D, Soussan P, Pineau P, Dejean A, Paterlini-Bréchot P, Tiollais P. 2010. Hepatitis B virus (HBV)-related hepatocellular carcinoma (HCC): Molecular mechanisms and novel paradigms. Pathol Biol 58: 278-287.

Chen M, Sällberg M, Thung SN, Hughes J, Jones J, Milich DR. 2001. Modeling the T-helper cell response in acute and chronic hepatitis $\mathrm{B}$ virus infection using T-cell receptor transgenic mice. Antiviral Res 52: 99-111.

Dandri M. 2001. Repopulation of mouse liver with human hepatocytes and in vivo infection with hepatitis B virus. Hepatology 33: 981-988.

Dandri M, Lütgehetmann M. 2014. Mouse models of hepatitis B and delta virus infection. J Immunol Methods 410: 39-49.

Dion S, Bourgine M, Godon O, Levillayer F, Michel M-L. 2013. Adeno-associated virus-mediated gene transfer leads to persistent hepatitis $B$ virus replication in mice expressing HLA-A2 and HLA-DR1 molecules. J Virol 87: $5554-5563$.

Ganem D, Prince A. 2004. Hepatitis B virus infection-Natural history and clinical consequences. N Engl J Med 350: $1118-1129$.

Grompe M, Strom S. 2013. Mice with human livers. Gastroenterology 145: 1209-1214.

Guidotti LG, Chisari FV. 2006. Immunobiology and pathogenesis of viral hepatitis. Annu Rev Pathol 1: 23-61.

Guidotti LG, Ando K, Hobbs MV, Ishikawa T, Runkel L, Schreiber RD, Chisari FV. 1994. Cytotoxic T lymphocytes inhibit hepatitis B virus gene expression by a noncytolytic mechanism in transgenic mice. Proc Natl Acad Sci 91: 3764-3768.

Guidotti LG, Matzke B, Schaller H, Chisari FV. 1995. Highlevel hepatitis B virus replication in transgenic mice. $J$ Virol 69: 6158-6169.

Guidotti LG, Ishikawa T, Hobbs MV, Matzke B, Schreiber R, Chisari FV. 1996. Intracellular inactivation of the hepatitis B virus by cytotoxic T lymphocytes. Immunity 4: 25-36.

Guidotti LG, Rochford R, Chung J, Shapiro M, Purcell R, Chisari FV. 1999. Viral clearance without destruction of infected cells during acute HBV infection. Science 284: 825-829.

Guidotti LG, McClary H, Loudis JM, Chisari FV. 2000. Nitric oxide inhibits hepatitis B virus replication in the livers of transgenic mice. 191: 1247-1252.

Guidotti LG, Inverso D, Sironi L, Di Lucia P, Fioravanti J, Ganzer L, Fiocchi R, Vacca M, Aiolfi R, Sammicheli S, et al. 2015. Immunosurveillance of the liver by intravascular effector CD8 ${ }^{+}$T cells. Cell doi:10.1016/j.cell.2015. 03.005 .

Heckel JL, Sandgren EP, Degen JL, Palmiter RD, Brinster RL. 1990. Neonatal bleeding in transgenic mice expressing urokinase-type plasminogen activator. Cell 62: 447-456.

Heise T, Guidotti LG, Cavanaugh VJ, Chisari FV. 1999a. Hepatitis B virus RNA-binding proteins associated with cytokine-induced clearance of viral RNA from the liver of transgenic mice. J Virol 73: 474-481. 
M. Iannacone and L.G. Guidotti

Heise T, Guidotti LG, Chisari FV. 1999b. La autoantigen specifically recognizes a predicted stem-loop in hepatitis B virus RNA. J Virol 73: 5767-5776.

Heise T, Guidotti LG, Chisari FV. 2001. Characterization of nuclear RNases that cleave hepatitis B virus RNA near the La protein binding site. J Virol 75: 6874-6883.

Huang Y-H, Fang C-C, Tsuneyama K, Chou H-Y, Pan W-Y, Shih Y-M, Wu P-Y, Chen Y, Leung PSC, Gershwin ME, et al. 2011. A murine model of hepatitis B-associated hepatocellular carcinoma generated by adeno-associated virus-mediated gene delivery. Int J Oncol 39: 1511-1519.

Iannacone M, Sitia G, Isogawa M, Marchese P, Castro MG, Lowenstein PR, Chisari FV, Ruggeri ZM, Guidotti LG. 2005. Platelets mediate cytotoxic T lymphocyte-induced liver damage. Nat Med 11: 1167-1169.

Iannacone M, Sitia G, Narvaiza I, Ruggeri ZM, Guidotti LG 2007a. Antiplatelet drug therapy moderates immunemediated liver disease and inhibits viral clearance in mice infected with a replication-deficient adenovirus. Clin Vaccine Immunol 14: 1532-1535.

Iannacone M, Sitia G, Ruggeri ZM, Guidotti LG. 2007b. HBV pathogenesis in animal models: Recent advances on the role of platelets. J Hepatol 46: 719-726.

Ilan E, Burakova T, Dagan S, Nussbaum O, Lubin I, Eren R, Ben-Moshe O, Arazi J, Berr S, Neville L, et al. 1999. The hepatitis B virus-trimera mouse: A model for human HBV infection and evaluation of anti-HBV therapeutic agents. Hepatology 29: 553-562.

Isogawa M, Furuichi Y, Chisari FV. 2005. Oscillating $\mathrm{CD}^{+} \mathrm{T}$ cell effector functions after antigen recognition in the liver. Immunity 23: 53-63.

Kakimi K, Lane TE, Wieland S, Asensio VC, Campbell IL, Chisari FV, Guidotti LG. 2001. Blocking chemokine responsive to $\gamma$-2/interferon (IFN)- $\gamma$ inducible protein and monokine induced by IFN- $\gamma$ activity in vivo reduces the pathogenetic but not the antiviral potential of hepatitis B virus-specific cytotoxic T lymphocytes. J Exp Med 194: 1755-1766.

Kosaka K, Hiraga N, Imamura M, Yoshimi S, Murakami E, Nakahara T, Honda Y, Ono A, Kawaoka T, Tsuge M, et al. 2013. A novel TK-NOG based humanized mouse model for the study of HBV and HCV infections. Biochem Biophys Res Commun 441: 230-235.

Kremsdorf D, Soussan P, Paterlini-Brechot P, Brechot C. 2006. Hepatitis B virus-related hepatocellular carcinoma: Paradigms for viral-related human carcinogenesis. Oncogene 25: 3823-3833.

Li H, Zhuang Q, Wang Y, Zhang T, Zhao J, Zhang Y, Zhang J, Lin Y, Yuan Q, Xia N, et al. 2014. HBV life cycle is restricted in mouse hepatocytes expressing human NTCP. Cell Mol Immunol 11: 175-183.

Lim WF, Inoue-Yokoo T, Tan KS, Lai MI, Sugiyama D. 2013. Hematopoietic cell differentiation from embryonic and induced pluripotent stem cells. Stem Cell Res Ther 4: 71.

Nakamoto Y, Guidotti LG, Kuhlen CV, Fowler P, Chisari FV. 1998. Immune pathogenesis of hepatocellular carcinoma. J Exp Med 188: 341-350.

Nakamoto Y, Suda T, Momoi T, Kaneko S. 2004. Different procarcinogenic potentials of lymphocyte subsets in a transgenic mouse model of chronic hepatitis B. Cancer Res 64: 3326-3333.
Raney AK, Eggers CM, Kline EF, Guidotti LG, Pontoglio M, Yaniv M, McLachlan A. 2001. Nuclear covalently closed circular viral genomic DNA in the liver of hepatocyte nuclear factor $1 \alpha$-null hepatitis B virus transgenic mice. J Virol 75: 2900-2911.

Rhim J, Sandgren E, Degen J, Palmiter R, Brinster R. 1994. Replacement of diseased mouse liver by hepatic cell transplantation. Science 263: 1149-1152.

Robek MD, Wieland SF, Chisari FV. 2002. Inhibition of hepatitis $B$ virus replication by interferon requires proteasome activity. J Virol 76: 3570-3574.

Robek MD, Boyd BS, Wieland SF, Chisari FV. 2004. Signal transduction pathways that inhibit hepatitis B virus replication. Proc Natl Acad Sci 101: 1743-1747.

Sette AD, Oseroff C, Sidney J, Alexander J, Chesnut RW, Kakimi K, Guidotti LG, Chisari FV. 2001. Overcoming $\mathrm{T}$ cell tolerance to the hepatitis $\mathrm{B}$ virus surface antigen in hepatitis B virus-transgenic mice. J Immunol 166: 13891397.

Shimizu Y, Guidotti LG, Fowler P, Chisari FV. 1998. Dendritic cell immunization breaks cytotoxic T lymphocyte tolerance in hepatitis B virus transgenic mice. J Immunol 161: $4520-4529$.

Sitia G, Isogawa M, Kakimi K, Wieland SF, Chisari FV, Guidotti LG. 2002. Depletion of neutrophils blocks the recruitment of antigen-nonspecific cells into the liver without affecting the antiviral activity of hepatitis B virusspecific cytotoxic T lymphocytes. Proc Natl Acad Sci 99: 13717-13722.

Sitia G, Isogawa M, Iannacone M, Campbell IL, Chisari FV, Guidotti LG. 2004. MMPs are required for recruitment of antigen-nonspecific mononuclear cells into the liver by CTLs. J Clin Invest 113: 1158-1167.

Sitia G, Iannacone M, Müller S, Bianchi ME, Guidotti LG. 2007. Treatment with HMGB1 inhibitors diminishes CTL-induced liver disease in HBV transgenic mice. $J$ Leukoc Biol 81: 100-107.

Sitia G, Iannacone M, Aiolfi R, Isogawa M, van Rooijen N, Scozzesi C, Bianchi ME, Andrian von UH, Chisari FV, Guidotti LG. 2011. Kupffer cells hasten resolution of liver immunopathology in mouse models of viral hepatitis. PLoS Pathog 7: e1002061.

Sitia G, Aiolfi R, Di Lucia P, Mainetti M, Fiocchi A, Mingozzi F, Esposito A, Ruggeri ZM, Chisari FV, Iannacone M, et al. 2012. Antiplatelet therapy prevents hepatocellular carcinoma and improves survival in a mouse model of chronic hepatitis B. Proc Natl Acad Sci 109: E2165-E2172.

Sprinzl MF, Oberwinkler H, Schaller H, Protzer U. 2001. Transfer of hepatitis B virus genome by adenovirus vectors into cultured cells and mice: Crossing the species barrier. J Virol 75: 5108-5118.

Sung W-K, Zheng H, Li S, Chen R, Liu X, Li Y, Lee NP, Lee WH, Ariyaratne PN, Tennakoon C, et al. 2012. Genomewide survey of recurrent HBV integration in hepatocellular carcinoma. Nat Genet 44: 765-769.

Tsui LV, Guidotti LG, Ishikawa T, Chisari FV. 1995. Posttranscriptional clearance of hepatitis B virus RNA by cytotoxic T lymphocyte-activated hepatocytes. Proc Natl Acad Sci 92: $12398-12402$.

Washburn ML, Bility MT, Zhang L, Kovalev GI, Buntzman A, Frelinger JA, Barry W, Ploss A, Rice CM, Su L. 2011. A 
humanized mouse model to study hepatitis $C$ virus infection, immune response, and liver disease. Gastroenterology 140: 1334-1344.

Wieland SF, Guidotti LG, Chisari FV. 2000. Intrahepatic induction of $\alpha / \beta$ interferon eliminates viral RNA-containing capsids in hepatitis B virus transgenic mice. $J$ Virol 74: 4165-4173.

Yan H, Zhong G, Xu G, He W, Jing Z, Gao Z, Huang Y, Qi Y, Peng B, Wang H, et al. 2012. Sodium taurocholate cotransporting polypeptide is a functional receptor for human hepatitis B and D virus. eLife 1: e00049.
Yang PL, Althage A, Chung J, Chisari FV. 2002. Hydrodynamic injection of viral DNA: A mouse model of acute hepatitis B virus infection. Proc Natl Acad Sci 99: 1382513830.

Yang D, Liu L, Zhu D, Peng H, Su L, Fu Y-X, Zhang L. 2013. A mouse model for HBV immunotolerance and immunotherapy. Cell Mol Immunol 11: 71-78.

Zhu S, Rezvani M, Harbell J, Mattis AN, Wolfe AR, Benet LZ, Willenbring H, Ding S. 2014. Mouse liver repopulation with hepatocytes generated from human fibroblasts. Nature 508: 93-97. 


\section{$\$ \mathrm{CSH} \&$ Cold Spring Harbor

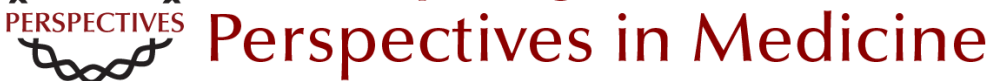

\section{Mouse Models of Hepatitis B Virus Pathogenesis}

Matteo lannacone and Luca G. Guidotti

Cold Spring Harb Perspect Med 2015; doi: 10.1101/cshperspect.a021477 originally published online August 20, 2015

Subject Collection The Hepatitis B and Delta Viruses

Hepatitis B Virus X and Regulation of Viral Gene Expression

Betty L. Slagle and Michael J. Bouchard

The Woodchuck, a Nonprimate Model for Immunopathogenesis and Therapeutic Immunomodulation in Chronic Hepatitis B Virus Infection

Michael Roggendorf, Anna D. Kosinska, Jia Liu, et al.

Mouse Models of Hepatitis B Virus Pathogenesis Matteo lannacone and Luca G. Guidotti

Therapy of Delta Hepatitis Cihan Yurdaydin and Ramazan Idilman

Immune Response in Hepatitis B Virus Infection Anthony Tan, Sarene Koh and Antonio Bertoletti

Hepatitis D Virus: Introduction and Epidemiology Mario Rizzetto

Management of Chronic Hepatitis B in Patients from Special Populations

Ching-Lung Lai and Man-Fung Yuen

Hepatitis B Virus Genotypes and Variants Chih-Lin Lin and Jia-Horng Kao
Origins and Evolution of Hepatitis B Virus and Hepatitis D Virus

Margaret Littlejohn, Stephen Locarnini and Lilly Yuen

Assembly and Release of Hepatitis B Virus Lisa Selzer and Adam Zlotnick

Hepatitis D Virus Replication John M. Taylor

Treatment of Liver Cancer Chun-Yu Liu, Kuen-Feng Chen and Pei-Jer Chen

Hepatitis B Virus and Hepatitis D Virus Entry, Species Specificity, and Tissue Tropism Koichi Watashi and Takaji Wakita

Hepadnavirus Genome Replication and

Persistence Jianming Hu and Christoph Seeger

The Chimpanzee Model for Hepatitis B Virus Infection

Stefan F. Wieland

Hepatitis B Virus Epidemiology

Jennifer H. MacLachlan and Benjamin C. Cowie

For additional articles in this collection, see http://perspectivesinmedicine.cshlp.org/cgi/collection/ 